\title{
A qualitative exploration of post-migration stressors and psychosocial well-being in two asylum reception centres in Belgium
}

\author{
Katherine Whitehouse, Ella Lambe, Sofia Rodriguez, Umberto Pellecchia, Aurelie Ponthieu, \\ Rafael Van den Bergh and Djoen Besselink
}

\begin{abstract}
Purpose - Prolonged exposure to daily stressors can have long-term detrimental implications for overall mental health. For asylum seekers in European Union transit or destination countries, navigating life in reception centres can represent a significant burden. The purpose of this study was to explore postmigration stressors during residency in reception centres, and to formulate recommendations for adequate service provision in Belgium.
\end{abstract}

Design/methodology/approach - Research was conducted in two reception centres in Belgium. A total of 41 in-depth interviews were carried out with asylum seeker residents $(\mathrm{n}=29)$ and staff $(\mathrm{n}=12)$. Purposive recruitment was used for asylum seekers (for variation in length of centre residency and family status) and staff (variation in job profiles). Interviews were conducted in English, French or with a translator in Arabic or Dari. Interviews were audio-recorded, transcribed verbatim and manually coded using thematic analysis.

Findings - Asylum seekers face significant constraints with regard to their living conditions, including total absence of privacy, overcrowding and unhygienic conditions. These act as continuous and prolonged exposure to daily stressors. Several barriers to accessing activities or integration opportunities prevent meaningful occupation, contribute towards eroded autonomy and isolation of asylum seeker residents. Inadequate capacity and resources for the provision of psychosocial support in reception centres leads to a sense of abandonment and worthlessness.

Originality/value - Analysis indicates that structural and practical challenges to adequately support asylum seekers are rooted in policy failures necessary for appropriate resourcing and prioritization of preventative measures. Such deliberate decisions contribute towards state deterrence strategies, eroding both individual well-being and manufacturing a crisis in the systems of support for asylum seekers.

Keywords Qualitative research, Well-being, Integration, Migration, Asylum seeker, Psychosocial, reception centre, Destination countries

Paper type Research paper

Introduction

Europe encompasses both transit and destination countries for asylum seekers. Globally in 2019, 79.5 million people were forcibly displaced, fleeing conflict, persecution or violence, with 4.1 million people awaiting a decision on their asylum claim (UNHCR, 2020). Collectively in European Union (EU) countries, 676,300 asylum seekers applied for international protection in the same period (Eurostat, 2020). Significant variations exist between EU countries in reception conditions for asylum seekers, leading to diverse outcomes for those using these different asylum systems (Rossenberger and Konig, 2011; European Council on Refugees and Exiles, 2017).

Residency and reception of asylum seekers in Belgium falls under federal jurisdiction, whilst integration policies are organized at a regional level (Flanders, Wallonia and Brussels). The
(Information about the authors can be found at the end of this article.)

Received 25 August 2020 Revised 11 December 2020 Accepted 12 January 2021

(c) Katherine Whitehouse Ella Lambe, Sofia Rodriguez, Umberto Pellecchia, Aurelie Ponthieu, Rafael Van den Bergh and Djoen Besselink. Published by Emerald Publishing Limited. This article is published under the Creative Commons Attribution (CC BY 4.0) licence. Anyone may reproduce, distribute, translate and create derivative works of this article (for both commercial and non-commercial purposes), subject to full attribution to the original publication and authors. The full terms of this licence may be seen at http://creativecommons org/licences/by/4.0/legalcode 
Federal Agency for the Reception of Asylum Seekers (Fedasil) receives asylum seekers once they have submitted their claim and is mandated by the Belgium Reception Act (January 2007) to provide accommodation, food, clothing, as well as access to essential social and legal support, medical and psychological care, and to services such as interpreters and training (Cour des comptes, 2017; Fedasil, 2018b). Of the 27,742 applications for international protection in Belgium during 2019, 34\% were yet to receive a decision within a year of filing for asylum (General Commission for Refugees and Stateless Persons (CGRA, 2018), and on average asylum seekers spend 13 months in reception centres prior to the asylum decision (Cour des comptes, 2017).

Asylum seekers are often confronted with traumatic experiences in their country of origin, during their journey or upon arrival in their destination country (MSF, 2017). The Inter-Agency Standing Committee has established guidelines for mental health and psychosocial support (Inter-Agency Standing Committee, 2007), setting out a framework to meet the needs through an inter-related layered system of complementary support (further details in Figure 1). To bridge a gap in addressing the health needs of asylum seekers and refugees, Hollifield et al. (2013) empirically developed the Refugee Health Screener-15 (RHS-15) as a standardized culturally competent, short tool for efficient and accurate "early screening and intervention for emotional distress among newly arrived refugees." The RHS-15 detects symptoms of anxiety and depression, including post-traumatic stress disorder. However, early screening for psychological distress among asylum seekers is rarely conducted and in most European settings, including Belgium, it is not currently standard practice to detect mental health conditions in parallel to screening tools for physical health. For definitions on key terminology used in this paper see below list:

Key definitions for terminology used in this paper

- Mental Health: A state of well-being in which an individual realizes his or her own abilities, can cope with normal stresses of life, can work productively and fruitfully, and is able to make a contribution to his or her community (World Health Organization, 2004).

Figure 1 IASC framework of inter-related mental health and psychosocial support

The wellbeing of an individual depends on the extent to which their basic physical, material and psychosocial needs are met (IASC, 2004). These inter-related needs are framed by IASC guidelines for mental health and psychosocial support (IASC, 2007) in a pyramid layered system of complementary support, addressing needs at four inter-connected levels through different mechanisms:

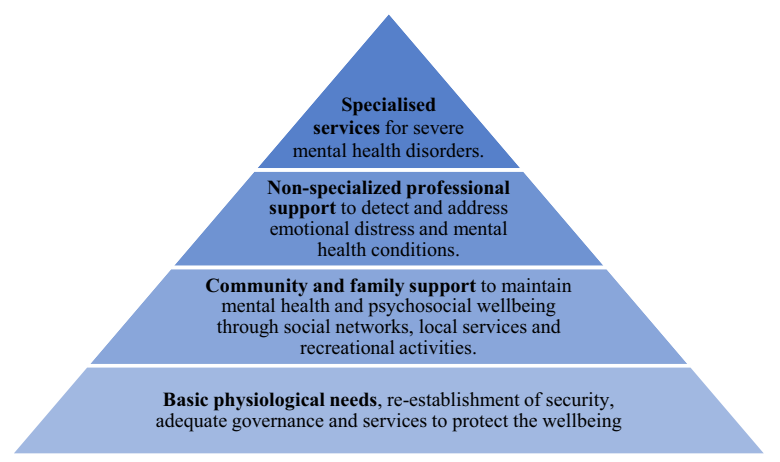

This framework is grounded in an integrated approach which recognizes the importance of addressing basic psychosocial needs, building resilience, activating coping mechanisms, and reducing significant mental distress. 
- Wellbeing: A state of happiness and contentment, with low levels of distress, overall good physical and mental health and outlook, or good quality of life. (American Psychological Association, 2020).

- Daily stressors: Understood as routine challenges, which may be minor yet tangible, of day-to-day life that are increasingly associated with negative mental health outcomes (Riley et al., 2017).

- Psychosocial wellbeing: A broad concept which understands wellbeing as influenced by internal and external factors, including the person's emotional, psychological, environmental, social and collective situation (Eiroa-Orosa, 2020).

- Psychological distress: A range of symptoms and experiences of a person's internal life that are commonly held to be troubling, confusing, or out of the ordinary (American Psychiatric Association, 2013).

- Psychosocial support: The objective of psychosocial support is to allow people to talk about their concerns (how to cope in a refugee camp, hospitalization, illness, loss, etc.) and to support positive coping skills (spending time with supportive others, establishing a routine, relaxation exercises, etc.). It can be implemented with individual beneficiaries or in group discussion. A group discussion gathers together people who have a common concern, e.g. a group of women. Group discussion offers a communal experience with an emphasis on reactivating community coping mechanisms and traditional practices (MSF working definition, 2020).

- Mental health and psychosocial support (MHPSS): Refers to any type of activity that aims to protect or promote psychosocial well-being of communities, to prevent the development of mental health conditions in high-risk populations, and to treat or alleviate psychological suffering, while enhancing functioning of people experiencing mental health problems and disorders. These goals are achieved by supporting people in using their strengths, developing their individual and collective adaptation strategies, reconnecting to their support networks and managing their emotions, through individual, group, family and community interventions. Humanitarian contexts, including natural and man-made disasters, epidemics, conflict situations and populations at risk for a variety of other reasons are associated with widespread experience of distress in the population and increased prevalence of mental disorder (MSF working definition, 2020).

"Following a request from Fedasil for additional medical provision for asylum seeker residents, Médecins Sans Frontières (MSF) conducted a needs assessment and determined that a package of mental health and psychosocial support (MHPSS) was urgently needed. Subsequently, from 2017 to 2018, MSF implemented activities in two asylum centres in Charleroi and Morlanwelz, Belgium. Programmatic data generated from systematic use of the RHS-15 identified $88 \%$ of people screened were in psychological distress, of whom $61 \%$ showed signs of severe distress. Further analysis indicated that the primary stressors identified were attributed to frustrations with asylum procedures and reception conditions, rather than to historical trauma prior to arrival in Belgium. Data also highlighted a correlation between extended stay in reception centres and deterioration of mental health.

The last decade has seen an increased focus on research into migration health in transit and destination settings within European contexts. Some of this work has sought to establish correlations between trauma experienced during displacement or transit with poor mental health outcomes (Eleftherakos et al., 2018). More recent emphasis has been placed on the critical role of post-migration stress and mental health (Carswell et al., 2011; Miller and Rasmussen, 2010). Daily stressors, primarily defined as the environmental, social or economic stressors not directly triggered by an emergency (Riley et al., 2017), have 
garnered greater attention. These can be understood as the hassle of daily life, with continuous and prolonged exposure to everyday low-level stress identified as more predictive of longer term psychological distress than major traumatic event (Miller and Rasmussen, 2010; Charles et al., 2013). However, MHPSS remains an under resourced and underprioritized part of health packages, both in terms of availability of services as well as the quality of care provided (Al Ajlan, 2020). This highlights the disconnect between the minimum standards prescribed by EU Directives and the increasing variability of services provided (Rossenberger and Konig, 2011). Whilst several works identify that the Belgiumspecific setting is an underexplored context (van Berlaer et al., 2016; Verroken et al., 2018), a recent contribution by Lietaert et al. (2020) has highlighted the specific inadequacy of communal reception centres for meeting the needs of families seeking asylum.

A previous systematic review identified that in humanitarian settings, the vast majority of MHPSS provision is implemented outside of formal national health structures (Tol et al., 2011). This research was conceptualized as part of the planned end of MSF's direct engagement and handover to Fedasil. Through exploring daily stressors in reception centres, this research aims to contribute towards the evidence needed for the prioritization of preventative strategies for an improved package of well-being and mental health support in asylum seeker populations in post-migration settings. Furthermore, the results formed a component of broader advocacy strategies with the relevant authorities for allocation of sufficient resourcing and prioritisation of MHPSS for reception centre residents.

\section{Materials and methods}

\section{Study design}

To investigate the role of daily stressors in the well-being of asylum seekers in the Belgian reception system, a qualitative exploratory study design was selected. This comprised of indepth interviews (IDIs) with asylum seekers currently residing in reception centres, and key informant interviews with Fedasil and MSF staff members of the reception centres.

\section{Study setting}

The study was conducted in Charleroi and Morlanwelz, two Fedasil reception centres, in the Wallonia region of Belgium. The centres had residential capacities of 170 and 196 places, run by 35 and 48 Fedasil staff members, respectively. MSF operated in each centre two days a week, reliant upon five key staff providing mental health services, health promotion, community mobilisation and social support activities. The PI (EL) occupied the position of Health Promotion Activity Manager, conceptualising the study collaboratively with MSF and Fedasil colleagues in positions of strategic and technical oversight.

\section{Study population and recruitment}

The study population comprised of current asylum seeker centre residents, and MSF and Fedasil staff. Asylum seekers were purposively recruited based on length of centre residency, gender, age and family status (unaccompanied or with at least one family member), to encompass diverse experiences. The selection criteria excluded the most vulnerable asylum seekers with mental health disorders or experiencing severe psychological distress to prevent undue harm. Fedasil staff members were purposively recruited based on job profiles to represent a variety of services available to asylum seekers, including medical, social, logistics and centre coordination. Asylum seekers and Fedasil staff were approached directly in the centres by members of the research team, with a translator when needed, and were invited to participate. All MSF project staff whose daily work involved contact with asylum seekers were invited to participate in the study. 


\section{Data collection and analysis}

IDI guides were developed, pre-tested and adapted prior to data collection. Several interconnected topics were explored: the rhythm of life in reception centres; the quality of the environment from physical, emotional and social perspectives; opportunities or barriers to activities; the development of interactions and integration with the host communities; experiences navigating asylum procedures and regulations; ability to exercise independence and autonomy; psychosocial well-being and coping mechanisms. All interviews were conducted by two female researchers (EL and KW) on an individual basis in either French or English, or for Dari or Arabic speakers with the assistance of a translator. Interviews were either conducted immediately after recruitment of study participants or at a later convenient time. Interviews took place in private rooms in the reception centres or at MSF headquarters. All interviews were audio-recorded and handwritten notes were taken. Data collection continued until no additional insights were gained and thematic saturation was reached.

Audio-recordings were transcribed verbatim, occurring simultaneously with data collection to allow for adaptations to interview guides and to strengthen the quality of data collected. For quality assurance, sections of each transcript were cross-checked against corresponding audio recordings. Manual coding of transcripts through a thematic analysis was conducted by two researchers (EL and KW) to establish the coding framework. In a continuous reflection process, statements were organised according to themes and subthemes, which were interpreted in relationship to each other. The final coding framework was discussed with the entire research team.

\section{Ethics}

During conceptualisation of the study and development of the protocol, several considerations for research ethics were explored through a detailed mapping of the risks to study participants through participation in the study, with corresponding mitigation plans put in place. In addition to procedural aspects, particular attention was paid to the potential for unintended harm, for example, weariness with answering questions on personal experiences, or feelings of unease, discomfort or distress with the topics explored. Ethics approval was granted by the MSF Ethics Review Board and the Universitair Ziekenhuis Antwerpen Ethics Committee. Prior to data collection time was taken to individually explore the risks and benefits of participating in the research, following which oral informed consent was sought from asylum seeker participants and written informed consent was provided by Fedasil and MSF staff.

\section{Results}

A total of 29 asylum seekers, eight Fedasil staff members and four MSF project staff participated in this study. At recruitment, three asylum seekers refused participation owing to lack of interest, whilst two staff members who agreed to participate were not available later on for an interview during data collection. An overview of socio-demographic data of study participants is detailed in Tables 1 and 2, with exact length of stay and residential details masked to ensure confidentiality of participants.

From the analysis of the data, we identified three main emerging themes related to daily stressors and well-being: 1) poor living conditions; 2) lack of engagement, integration and autonomy; 3 ) inadequate capacity and resources to provide psychosocial support.

\section{Poor living conditions}

It was acknowledged by asylum seeker participants that they could not expect "all the comforts in the world" and that their situation was "good for now." However, whilst basic 
Table 1 Description of asylum seeker participants organized according to centre of residence

\begin{tabular}{|c|c|c|c|c|c|}
\hline Participant code & Fedasil centre & Sex & Nationality & Status (single/family) & Length of residence \\
\hline 1 & A & $\mathrm{F}$ & Venezuela & Single & $<3$ months \\
\hline 2 & $A$ & $M$ & DR Congo & Single & $<12$ months \\
\hline 3 & $A$ & $\mathrm{~F}$ & Cameroon & Family & $<6$ months \\
\hline 4 & A & $\mathrm{F}$ & DR Congo & Single & $<12$ months \\
\hline 5 & $A$ & M & Afghanistan & Single & $<6$ months \\
\hline 6 & $A$ & $\mathrm{~F}$ & Central African Republic & Single & $<30$ months \\
\hline 7 & A & M & Afghanistan & Single & $<12$ months \\
\hline 8 & $A$ & M & Afghanistan & Single & $<18$ months \\
\hline 9 & A & M & Venezuela & Single & $<18$ months \\
\hline 10 & $A$ & $\mathrm{~F}$ & Afghanistan & Single & $<3$ months \\
\hline 11 & $A$ & M & Palestine & Single & $<3$ months \\
\hline 12 & A & M & Syria & Single & $<3$ months \\
\hline 13 & $A$ & $M$ & Syria & Family & $<6$ months \\
\hline 14 & B & $\mathrm{F}$ & Ivory Coast & Family & $<12$ months \\
\hline 15 & B & $\mathrm{F}$ & Djibouti & Single & $<12$ months \\
\hline 16 & $\mathrm{~B}$ & $\mathrm{~F}$ & Iraq & Family & $<12$ months \\
\hline 17 & B & M & Angola & Family & $<12$ months \\
\hline 18 & $\mathrm{~B}$ & M & Kosovo & Family & $<6$ months \\
\hline 19 & $\mathrm{~B}$ & $\mathrm{M}$ & Djibouti & Single & $<30$ months \\
\hline 20 & $\mathrm{~B}$ & $\mathrm{M}$ & Iraq & Family & $<12$ months \\
\hline 21 & $\mathrm{~B}$ & $\mathrm{~F}$ & DR Congo & Single & $<3$ months \\
\hline 22 & $\mathrm{~B}$ & $\mathrm{~F}$ & Cameroon & Family & $<18$ months \\
\hline 23 & B & M & Palestine & Single & $<6$ months \\
\hline 24 & $\mathrm{~B}$ & $\mathrm{~F}$ & DR Congo & Family & $<12$ months \\
\hline 25 & $\mathrm{~B}$ & $\mathrm{M}$ & Afghanistan & Single & $<30$ months \\
\hline 26 & B & $\mathrm{F}$ & Guinea & Single & $<18$ months \\
\hline 27 & B & $\mathrm{F}$ & Cameroon & Family & $<18$ months \\
\hline 28 & B & $M$ & Senegal & Single & $<6$ months \\
\hline 29 & $\mathrm{~B}$ & $\mathrm{~F}$ & Palestine & Single & $<3$ months \\
\hline
\end{tabular}

Table 2 Description of Fedasil and MSF staff participants organized according to centre of work

\begin{tabular}{lllll} 
Organisation & Participant code & Fedasil centre & Sex & Professional profile \\
\hline Fedasil & 1 & $\mathrm{~A}$ & $\mathrm{M}$ & Coordination, administration or logistics \\
Fedasil & 2 & $\mathrm{~A}$ & $\mathrm{~F}$ & Medical and social \\
Fedasil & 3 & $\mathrm{~A}$ & $\mathrm{M}$ & Coordination, administration or logistics \\
Fedasil & 4 & $\mathrm{~A}$ & $\mathrm{~F}$ & Community and outreach \\
Fedasil & 5 & $\mathrm{~B}$ & $\mathrm{M}$ & Medical and social \\
Fedasil & 6 & $\mathrm{~B}$ & $\mathrm{M}$ & Medical and social \\
Fedasil & 7 & $\mathrm{~B}$ & $\mathrm{M}$ & Coordination, administration or logistics \\
Fedasil & 8 & $\mathrm{~B}$ & $\mathrm{~F}$ & Medical and social \\
MSF & 1 & $\mathrm{~A}$ and B & $\mathrm{M}$ & Medical and social \\
MSF & 2 & $\mathrm{~A}$ and B & $\mathrm{F}$ & Medical and social \\
MSF & 3 & $\mathrm{~A}$ and B & $\mathrm{M}$ & Community and outreach \\
MSF & 4 & $\mathrm{~A}$ and B & &
\end{tabular}

needs (safe place to sleep, essential health care or food) were provided, several detrimental environmental constraints were reported by the majority of asylum seeker participants.

Lack of privacy was identified as extremely challenging. For unaccompanied people in these two centres, up to six individuals occupied a dormitory style room, whilst whole families were accommodated in a single room. Crowded rooms, shared with people who had different daily rhythms, habits or personalities often led to tensions. For some, this was 
exacerbated by different cultural expectations and the lack of a common language, which limited communication. Friction was further amplified by the absence of calm places in the centre to retreat to outside of the shared room. An overarching sense of insecurity was cited as particularly damaging for families whereby their children grow up within an atmosphere defined by insecurity and inter-personal conflict. In the one centre that had a library, TV rooms and other separated spaces, these facilities were often referred to as sources of comfort.

If you cry, everyone sees you. There is no privacy, there is none (Asylum seeker 1, female, Venezuela).

[...] the daily stressors, which are basically the life conditions they have in the centre, at the end of the day when you speak to them you realise their biggest problem right now is the fact that they don't feel comfortable sharing rooms or not being able to lock their doors, or not having hot water, or not having access to communication [translation] when having a medical appointment (MSF staff 3, female, medical and social profile).

Widespread dissatisfaction over the monotony and poor quality of food on offer through the catering system was reported, and staff members were also aware of this frustration. The food was deemed unpalatable, which was particularly pronounced for parents owing to the sensitivity of children to disrupted or deviated cultural eating practices. Most asylum seekers resorted to purchasing supplementary food because they were hungry. Many participants felt further constrained by the imposed meal times and the lack of cooking facilities. Asylum seekers suggested to either adapt the menus on offer (through consultation) or provide money and cooking facilities. This was identified as a solution to reduce food waste, which caused deep discomfort with certain participants.

Poorly maintained and unhygienic shared sanitation facilities were described as a further source of unease, linked both to tensions with fellow centre residents over their cleaning habits and staff for their incapacity or unwillingness to solve these issues. The quality of the facilities in the centres was described among asylum seekers as sub-optimal, with old buildings in disrepair and restrictions on infrastructural investment. Fedasil staff detailed that it was not within their control to improve the facilities and that these were adversities that needed to be endured rather than addressed. It was suggested by a couple of Fedasil and MSF participants that the poor quality of the physical environment was an intentional strategy to deter current and future residents from pursuing their application for asylum. Several asylum seekers self-reported that their health, including their mental health, had deteriorated since arriving in Belgium, linking this to the living conditions. Staff participants from medical or social care backgrounds were able to describe how some asylum seekers felt worse with continued exposure to the stress of communal living, presenting symptoms of distress which were not present before. These included numerous forms of somatic pain, chronic sleeping problems and withdrawal. Widespread symptoms of distress prompted several participants to reflect that fundamentally what was needed were rapid rulings on international protection to limit both protracted uncertainty as well as exposure to daily stressors.

We know that it's not easy. For food, for the cohabitation, for this for that [...] But you just have to think that it is a moment in their life, more or less long, and at least they have food, a roof over their head and they are safe. (Centre staff 7, male, coordination, administration or logistics profile)

Two days ago a girl was coming to me to say "I run away from my country because it's not safe, and I thought I'm going to be in a better place, but finally I wish that I died in my country instead of coming here [...] I feel my health in my country, when I was in danger, was much better than here". (MSF staff 2, male, medical and social profile)

[... ] it's very common to listen to asylum seekers saying they've never felt worse than how they're feeling right now. And you think how is it possible, if you've gone through hell in other situations? (MSF staff 3, female, medical and social profile) 


\title{
Lack of engagement, integration and autonomy
}

Multiple barriers to initiate educational opportunities, or professional development training, find employment, or participate in useful activities or other forms of entertainment (either inside or outside the centre) were identified by all study participants. The main contributing factors were overly bureaucratic and administrative procedures, negative attitudes of staff or other officials and incomprehensible rules on the use of communal spaces. A key difference identified between individual residents and those living with their family was the additional burden and responsibility for children, which limited their potential to take up the few existing opportunities and activities. Without occupation, residents of the centres become bored and frustrated. Keeping active was described as a way to cope with both previous traumatic experiences as well as their current challenges of length of stay and inadequacies of the reception environment. Some emphasised the importance of emotional or mental coping strategies, for example, "change your ideas," "forget" or "chase negative thoughts," to maintain their well-being. In addition to the geographical isolation of the centres, participants noted that asylum seekers' mobility was further restricted through limited public transport networks and prohibitive costs.

They do not sleep well, they do not eat well, and they do not have leisure activities. They are shut up here all the time. Every now and then, they come to a medical [consultation] saying they are in pain [... . that way they will get an external appointment, they will get a [transport] ticket. (Centre staff 2, female, medical and social profile)

\begin{abstract}
I have been here for two and a half years now [...] it was not too difficult, but these last three months it was too difficult. Before, I went to school, I spoke to friends, I played football [...] but for the last three months I have stopped everything. Then I'm not feeling good in my head. Sometimes I forget many things and I think about my family, the procedures [...]. (Asylum seeker 25, male, Afghanistan)
\end{abstract}

I keep myself busy. This is the difference [. . . If I am not going to make contact with people [...] or if I have free time, I will go in this deep depression. This will make me like a zombie (Asylum seeker 29, female, Palestine).

To me [the centres] are a bit like waiting rooms and I would try to turn them more into living rooms. Like actual places where people can live and maybe enjoy [...] to make the most out of the time, learn something, improve certain skills, learn a new language, engage with other nationalities and people, create a nice space for mothers and their children (MSF staff 1, female, medical and social profile).

In spite of wide recognition that spending time outside the centre was key to reducing tensions caused by reception conditions, only two asylum seeker participants described that they had been able to develop personal connections with people living in the local community. Maintaining these new relationships, or even those with previously established support networks, were uncertain owing to geographical isolation and limited internet access. Furthermore, newly or previously established connections with non-residents were marred by a sense of separation, given external people were unable to fully comprehend and empathise with the situation in the centre. Feeling useful, helping others and integration within the community were identified as positive mechanisms to establish human connection. However, with these opportunities largely unavailable, several participants expressed that, as asylum seekers, they felt they were not valued by the wider host society.

When you are limited, you feel incapable! I know that in my country with the diploma that I have I would be sought after. Whereas here they don't care what you have in your head, what diplomas you have. You are in the refugee category and that is it. They don't care about what you are capable of doing (Asylum seeker 6, female, Central African Republic). 
[Asylum seekers] have skills and I think that we let them stagnate, we don't engage them really, and that is a shame (Fedasil staff 1 , male, coordination, administration or logistics profile).

Frustration in particular was centred on access to language training or translation services. Staff identified that the development of local language competencies are essential for the person's integration, feeling of belonging and well-being, but in practice little emphasis was placed on facilitating access to courses. Instead multiple barriers to initiate formal language tuition were encountered by asylum seekers, including lengthy waiting lists and confusing administrative procedures. Whilst some asylum seeker participants had attempted to join online courses, poor-quality internet prevented optimal use of these tools.

You need to wait. It's always "wait, wait", [...] but here there is nothing. I went out to the park, because there is nothing else to do. Honestly, for me it is sad here to waste time. You waste time. And you wait, you wait, you wait (Asylum seeker 9, male, Venezuela).

Ultimately, residents expressed deep dissatisfaction with the limited independence in their daily life. Negotiating for basic services and reliance on inadequate support was deemed humiliating, with several references made to being treated like "prisoners" or "children." Interviews detailed an environment of confinement and surveillance, with diminished personhood through total reliance on the asylum system. Both Fedasil and MSF staff participants identified a link between deliberately selected organisational approaches and the undermining of the residents' exercise of control over daily decisions. One participant described the situation as a "fake crisis," ultimately the result of political decisions over the design of reception systems. Frustration around the absence of consultation was widespread, with several calls for more involvement of asylum seekers in developing the regulations that dictate their daily life.

For everything and for nothing you have to ask. Frankly, it's like we are begging. Me I've never asked like that in my life [.. . I I am ashamed of going each time [and hearing] 'yes yes, but wait wait'. That is what hurts me the most (Asylum seeker 18, male, Kosovo).

First when you come, okay, I'm safe now. Nobody's going to shoot me. No rockets over my head. After that you start looking. You feel like your life is being controlled. The food. The movement. Freedom. Sleeping in the room. You start comparing it with a prison (Asylum seeker 11, male, Palestine).

So many decisions are just taken from them. .. they're completely dependent on the centre, the residents, and this doesn't encourage autonomy or decision making (MSF staff 1, female, medical and social profile).

\section{Inadequate capacity and resources to provide psychosocial support}

Participants identified several suboptimal, and at times detrimental, examples of inadequate capacity to provide psychosocial support in reception centres. These pertain to a combination of fractious relationships between staff and asylum seekers, and the limited time, resources and competencies of staff to recognise and address psychosocial needs.

Communications between staff and asylum seekers were repeatedly identified as inadequate and inconsiderate. For asylum seeker participants, staff attitude and availability were perceived as key to a positive relationship and a sign of respect. Staff were perceived as not communicating in sufficiently respectful ways, leading asylum seekers to respond negatively with feelings of animosity towards either the system or the staff enforcing it. Often linked to poor communication between staff and asylum seekers, participants reported an atmosphere of widespread insensitivity to their 
needs. Over time this contributed to feelings of worthlessness, isolation and abandonment.

In the centres, they are just protecting your life, not to die. That's it. But, to be honest, it kills your emotions inside [...] You don't feel your value [...] When you see a dog worth more than you. [...] You feel that they [Fedasil staff members] are happy you are living in this situation and they laugh at you a lot when you come to talk to them. You wish that one of them would come and listen to you, listen to your story (Asylum seeker 11, male, Palestine).

Some staff participants indicated an awareness of the necessity to be accessible to asylum seekers, noting the importance of opportunities to speak and be listened to. They recognized that presenting a supportive attitude and being reactive to their needs was a source of reassurance and re-establishing a sense of worth. A minority of asylum seeker participants were empathetic of staff working under difficult conditions, noting some went above and beyond what is commonly expected of them in their roles, particularly with attention to small details or politeness. However, more commonly, they perceived that staff were not effective in their work, characterised by long delays for limited action.

\footnotetext{
We need to be tolerant because we do not know how they arrived here, what happened, so we need to take our time, in order not to rush [them] (Centre staff 4, male, community and outreach profile).

It must be a shock with everything that we tell them when they arrive, "you will have the right to see a doctor" and then they go to the medical service and it is "not today," "not today," "not today." "You will have a social worker" then "he or she is sick and there is no one to replace them." "You will have the right to go to school," "no, the training has already started, you'll have to wait until September or next year" (Centre staff 7, male, coordination, administration or logistics profile).
}

Across all participant groups there was agreement that reception centre staff face several difficulties to provide adequate psychosocial support to asylum seekers, from both preventative and curative perspectives. Some workers described feeling limited in this aspect owing to a lack of time, emphasising that their workload and increasing expectations of the system did not allow them to be as engaged with residents as they would like. Others described a lack of knowledge or materials that could support them, feeling under-skilled to meet residents' needs. Ultimately, these factors limited the quality of the support they were able to provide, which was repeatedly identified as inadequate. A small number of staff participants shared their views that intentionally limited resource allocation, and particularly for MHPSS, exacerbated the underlying vulnerability of individuals and families living in inadequate reception centres. From the perspective of asylum seekers, this lack of capacity, in terms of time and skills, was understood as a lack of interest to provide adequate psychosocial support. Poor communications were further exacerbated by the lack of available translators, thereby limiting access to essential services and information.

Often we are so busy with the medical work that we miss a lot of the psychological needs and that is very sad. We really do not have the time. [...] Before when someone told me "I have a headache" I used to sit down and chat a bit with them. Now "I have a headache", I quickly go to get a paracetamol and I give it to them because I know I have 10 or 15 other residents to see (Centre staff 2, female, medical and social profile).

They don't listen to us, they don't listen to us. They come just to take the salaries and they go (Asylum seeker 7, male, Afghanistan).

If you don't speak French, then your access to medical care, to be referred to a psychologist or a psychiatrist, you have a very low chance because they cannot find someone to speak Arabic or someone who would work with a translator. And most females who experienced 
trauma or violence, they prefer to speak with a woman, but this is not always possible. So, there are limitations to access services or benefit from the available solutions (MSF staff 2, female, medical and social profile).

\section{Discussion}

Previous work on migration by social scientists has argued how reception conditions play an integral role in shaping new forms of subjectivities amongst asylum seekers (Kibreab, 1999, 2002). These are created within a space of tensions and power dynamics, where regulations - from every day-to-day life activities to navigating legal procedures - constantly enact pressure on the capacity of the asylum seekers to express themselves (Malkki, 1995, 1996). Our research furthers these works by identifying major constraints in Belgium's approach to providing assistance to asylum seekers in reception centres, with specific identification of the daily stressors to which asylum seekers are continuously exposed. Our analysis suggests that the challenges of undignified living conditions are symptomatic of the broader policy issues that inform reception resourcing and provision. In Belgium, the recent political landscape has created a narrative around migration that negatively portrays the asylum procedure as a "waiting room" (Francken, 2018) rather than a legal process prescribed by laws. In this discussion, we highlight that both inadvertent and deliberate barriers prevent the achievement of conditions that would be favourable to well-being in the Belgium reception centres, and that policy, structural and practical shifts are required to achieve a more person-centred approach. Whilst individual and structural aspects are interwoven, here we focus on four main axes comprising communication and empowerment, autonomy, social integration and a wider focus on well-being.

With limited language proficiencies and translation, we found that meaningful communication between asylum seekers and reception staff is detrimentally affected. Asylum seekers perceive that staff are unavailable and unreactive to their needs, which fosters an environment of frustration and distrust. Not only does this detrimentally affect residents but also staff find themselves working in a highly stressful environment, which they have little or no power to change. Worryingly, timely access to medical, social or legal support is prohibited by these communication barriers. This echoes previous data that language safeguards asylum seeker access to essential services and support networks (Salvo and Williams, 2017), and that asylum seekers face significant barriers to developing language proficiency whilst in reception centres (Caritas International, 2014). Related evidence from a meta-analysis has shown that where interpreters or translators are not available, the ability to articulate the singularities of different refugee groups and the understanding of their specific difficulties is hampered (Galina et al., 2017). Both structural inefficiencies and policy failures prevent reception centre staff from providing flexible access to sufficient language training or translation services. These factors inhibit efficient functioning, reinforcing resentment on both sides and limiting motivation to accommodate resident needs. Prioritising resources for communication would ensure asylum seekers feel respected and adequately supported, whilst increased access to language training programmes would reduce dependency on translation services by promoting self-sufficiency and autonomy in communications.

With almost every aspect of the asylum seeker's life dictated by the rules of the centre and of the asylum system, near total dependency of residents is assured. Similar to observations from other EU countries (Rossenberger and Konig, 2011; Al Ajlan, 2020; van der Horst, 2004), we found that the Belgium system is geared towards the control of reception centre residents, marked by waiting, confinement and surveillance. This can be seen as the implementation of an approach understood as "total institutions" [1], whereby individual personhood is eroded through varying degrees of communal life. 
Elsewhere, there have been increasing calls for the consultation and involvement of asylum seekers in the design and adaptation of support services (Majumder et al., 2015) and the policies that concern them (Salvo and Williams, 2017). Whilst one of Fedasil's founding principles is "guidance of clients," with the provision of effective and quality support to encourage autonomy and responsibility (Posselt et al., 2018), our findings show that in an absence of sufficient resourcing and flexible bureaucracy there are considerable challenges for staff to foster an environment conducive for individual agency and decision-making. Few possibilities exist for asylum seekers to influence their environment, maintaining the predominantly negative view that they are passive individuals whose only purpose is to wait for the outcome of their asylum claim. Furthermore, we find that problematic hierarchies of power between reception centre staff and asylum seeker residents are reinforced. This is an integral component of "othering" narratives in dominant discourse which shapes collective mis-understanding and hostility towards people seeking protection in destination contexts, as described in the work of van der Horst (2004). The introduction of genuine mechanisms to engage asylum seeker skills and perspectives, such as participatory approaches to governance in reception centres, would promote autonomy during residency.

Whilst recent research conducted in transit countries has identified experiences of debilitating limbo among asylum seekers (Eleftherakos et al., 2018), through our research we find that even in Belgium, a destination country, asylum seekers are subjected to remarkably similar environments of prolonged and uncertain waiting. With restrictions on communications, mobility and occupation, asylum seekers lack the key external enabling factors to improve their well-being during residency in reception centres through the development of networks and relationships within the host community. Access to telecommunications and information technology has been found to contribute to migrant populations maintaining social connections and a sense of identity (Branco, 2018; and as such is considered critical. Whilst labour market integration is a key indicator for wider integration of asylum seekers into host communities (Hvidtfeldt et al., 2018), this process can be strongly inhibited by the limbo of a long asylum process (Hainmueller et al., 2016). Positive experiences of access to services, building partnerships and achieving integration that we identified in this study were exceptional, exposing an insufficient prioritisation of support to asylum seekers and mobilising their own resources. Legal access to the labour market alone does not facilitate economic integration for asylum seekers, measures of support (Hainmueller et al., 2016) and the development of social networks (Eisnecker and Schacht, 2016) are also necessary, which we highlight would be beneficial in this context. Lack of autonomy was particularly pronounced for asylum seekers with primary care responsibilities for families, reinforcing recently raised concerns that communal reception centres are entirely inappropriate for families (Lietaert et al., 2020).

Where a strategy exists, priority is often placed on emergency mental health provision (Rossenberger and Konig, 2011), or curative and specialised mental health care (MSF, 2017). We argue that an implementation logic based on EU Directives defining minimum standards significantly hinders the deployment of preventative approaches. Furthermore, whilst care for asylum seekers suffering from mental health disorders should remain a central objective, a reception system focusing primarily on traumas that occurred prior to and during migration can distract from the important role postmigration reception conditions have on well-being. Al Aljan (2020) highlighted the contradiction of longer term mental health-care needs and the notion of temporary reception centres, echoing this research which identifies a myriad of factors and daily stressors that can contribute to deterioration of well-being. These include poor living conditions, impaired communications, a lengthy asylum application process, isolation and dependency. Other research findings suggest that such post-migration experiences indeed contribute to psychological burden and exacerbate mental health 
issues (Carswell et al., 2011; Crepet et al., 2017; Giacco et al., 2018; Hassan et al., 2016; Hoare et al., 2017). Ensuring mental well-being for asylum seekers requires that post-migration stressors associated with developing depression or other mental disorders are identified and mitigated (Miller and Rasmussen, 2010; WHO, 2018). However, this requires the availability of competent staff with supportive management structures and training opportunities to implement quality services. Our research highlights that whilst individual staff invest considerable effort to provide high standards of care, there is a fragmentation of their efforts, lacking coordination and they often occur in isolation without guidance from coherent institutional policies. Research in Germany identified wholly inadequate quality of mental health provision, predominantly derived from euro-centric approaches and poorly adapted to the needs of individuals from diverse contexts and complex histories (Al Ajlan, 2020). Continued over reliance on minimum standards of care will continue to fail individuals trapped in unnecessarily lengthy procedures and poor living conditions.

Cumulatively, these results of our study can be understood as the outputs of the broader policies of deterrence, enacted both by Belgium and other EU member states. Through focusing, almost entirely, upon the provision of basic assistance in line with minimum standards, meaningful commitment to refugee protection through preventative health-care and person-centred services are neglected. Whilst we are not the first to emphasise that these are manufactured failures from intentional policy decisions, we aim to contribute to the necessary continued efforts to constructively challenge the political landscape and transform the living and working conditions of those engaged with reception centres on a daily basis.

\section{Limitations}

Several efforts were taken to recruit a variety of perspectives through recruitment procedures, however, a number of specific profiles were either absent or underrepresented in this study. The experiences of individuals not fluent in Arabic, Dari, English or French were not captured by this research owing to the language competencies of the research team and translators available. The selection criteria excluded the most vulnerable asylum seekers with mental health disorders or experiencing severe psychological distress to prevent undue harm; as these people were not interviewed, the perspectives of this particular group were not included. Asylum seekers who are more engaged with the host country through work, training or other activities spend less time in the centres, limiting recruitment and study participation opportunities for these individuals. Finally, minors were not included in this study, as their age and the specific support provided for them, means that their experience differs significantly from adults, requiring a separate dedicated study.

\section{Conclusions and recommendations}

Encountered challenges of inadequate mental health services, undignified living conditions and an absence of personal autonomy are symptomatic of major failures in Belgium's approach to providing appropriate assistance for asylum seekers in reception centres. We highlight that both inadvertent and deliberate barriers prevent residents from achieving well-being, with both self-reported and professional indication that an unstable and unsupportive environment is created, which likely contributes to a deterioration of mental well-being over time. This study emphasises the necessity to redefine the broader policy landscape that informs reception resourcing and provision, where structural and practical shifts would achieve a more person-centred approach.

In Belgium, the recent political environment has created a narrative around migration that promotes predominantly negative depictions of asylum seekers as dependent and passive 
recipients of assistance. Transformation towards a framework which fosters inclusive approaches to engagement of asylum seekers in asylum processes would promote personal autonomy, facilitate community integration and assure more dignified treatment of individuals during residency.

\section{Acknowledgements}

It is because of the support and interest of Fedasil to investigate the research question that permission was granted to access these study sites. The authors sincerely thank them for allowing to do so and for their continued commitment to provide care to asylum seekers residing in reception centres in Belgium. The research team would like to acknowledge the invaluable contributions of the study participants for this research. By generously sharing their time and perspectives on a voluntary basis, the asylum seeker participants, Fedasil centre staff and members of the MSF project team have provided the authors with rich insight into the topics explored. Timely processing of the data collected would not have been possible without the dedication of the volunteer transcribers, and The authors are grateful for their support. The authors would also like to thank their MSF colleagues, Sylvie Fagard-Sultan (Mental Health Referent) and Tony Reid (Medical Editor), for their technical and editorial inputs on the final paper.

Funding: This research was conducted through the Structured Operational Research and Training Initiative (SORT IT), a global partnership led by the Special Program for Research and Training in Tropical Diseases at the World Health Organization (WHO/TDR). The model is based on a course developed jointly by the International Union Against Tuberculosis and Lung Disease (The Union) and Médecins Sans Frontières (MSF/Doctors Without Borders). The specific SORT IT training program and open access publication costs was funded by the La Fondation Veuve Emile Metz-Tesch (Luxembourg). The funders had no role in study design, data collection and analysis, decision to publish or preparation of the manuscript.

Data availability statement: The data that support the findings of this study are available from the corresponding author, KW, upon reasonable request.

Declaration of interest statement: The authors declare they have no competing interests.

Author contributions: EL designed the study protocol which was then critically reviewed by UP and KW. EL and KW were involved with acquisition of data and data analysis. Additional interpretation of data was provided by $\mathrm{DB}, \mathrm{SR}$ and $\mathrm{RVdB}$, The first draft of the manuscript was written by EL and KW, with further inputs and critical review by DB, UP, AP, SR and RVdB. KW handled final revisions which were reviewed by all authors.

All authors approved the final version and are accountable for the final manuscript.

\section{Note}

1. The term "total institutions" was term popularised by sociologist Erving Goffman during the 1950s-1960s, proposing that similarly situated people, isolated from the broader population, develop an independent or isolated approach to collective life. In the 1970s, the philosopher Michel Foucault continued this concept in his exploration of prisons, understood as complete and austere settings.

\section{References}

Al Ajlan, A. (2020), "The asylum procedure in Germany: desperation and uncertainty as risk factors for violence among young adult asylum seekers in collective accommodations", Journal of Interpersonal Violence, pp. 1-25, doi: 10.1177/0886260520957976.

Branco, I. (2018), "Media and the receiving country's language: the integration of Nepalese immigrants in Portugal", in Karim, K. and Al-Rawi A. (Eds), Diaspora and Media in Europe, Palgrave Macmillan, Cham. 
Caritas International (2014), Réfugié ch. Travail - Résultats D'une Étude Sur la Formation et L'emploi Menée Auprès de Réfugiés, Caritas International, Brussels.

Carswell, K., Blackburn, P. and Barker, C. (2011), "The relationship between trauma, post-migration problems and the psychological well-being of refugees and asylum seekers", International Journal of Social Psychiatry, Vol. 57 No. 2, pp. 107-119, [Research Support, Non-U.S. Gov’t].

CGRA (2018), Statistiques D' asile Décembre 2018, Commissariat général aux réfugiés et aux apatrides, Brussels.

Charles, S.T., Piazza, J.R., Mogle, J., Sliwinski, M.J. and Almeida, D.M. (2013), "The wear and tear of daily stressors on mental health", Psychological Science, Vol. 24 No. 5, pp. 733-741, available at: www.ncbi. nlm.nih.gov/pmc/articles/PMC3654031

Cour des comptes (2017), Accueil Des Demandeurs D'asile, Cour des comptes, Brussels.

Crepet, A., Rita, F., Reid, A., Van den Boogaard, W., Deiana, P., Quaranta, G. and Di Carlo, S. (2017), "Mental health and trauma in asylum seekers landing in Sicily in 2015: a descriptive study of neglected invisible wounds", Conflict and Health, Vol. 11 No. 1, p. 1.

Eisnecker, P. and Schacht, D. (2016), "Half of the refugees in Germany found their first job through social contacts", DIW Economic Bulletin, Vol. 6 Nos 34/35, pp. 414-421, available at: www.econstor.eu/handle/ $10419 / 146522$

Eleftherakos, C., van den Boogaard, W., Barry, D., Severy, N., Kotsioni, I. and Roland-Gosselin, L. (2018), "I prefer dying fast than dying slowly, how institutional abuse worsens the mental health of stranded Syrian, Afghan and Congolese migrants on Lesbos island following the implementation of EU-Turkey deal", Conflict and Health, Vol. 12 No. 1, p. 38.

European Council on Refugees and Exiles (2017), "Refugee rights subsiding? Europe's two-tier protection regime and its effect on the rights of beneficiaries", available at: https://asylumineurope.org/ wp-content/uploads/2020/11/aida_refugee_rights_subsiding.pdf

Eurostat (2020), "Asylum statistics", available at: https://ec.europa.eu/eurostat/statistics-explained/ pdfscache/5777.pdf (accessed 13 May 2020).

Fedasil (2018b), "Nos valeurs", available at: www.fedasil.be/fr/propos-de-fedasil/nos-valeurs (accessed 3 September 2018).

Francken, T. (2018), "Former Belgian state secretary for asylum and migration (2014-2018)", available at: https://twitter.com/FranckenTheo/status/972817776959197184

Galina, V.F., da Silva, T.B.B., Haydu, M. and Martin, D. (2017), "Literature review on qualitative studies regarding the mental health of refugees", Interface Commun Health Educ, Vol. 21 No. 61, pp. 297-308.

Giacco, D., Laxhman, N. and Priebe, S. (2018), "Prevalence of and risk factors for mental disorders in refugees", Seminars in Cell \& Developmental Biology, Vol. 77, pp. 144-152.

Hainmueller, J., Hangartner, D. and Lawrence, D. (2016), "When lives are put on hold: lengthy asylum processes decrease employment among refugees. [research support, Non-U.S. Gov't]", Science Advances, Vol. 2 No. 8, p. e1600432.

Hassan, G., Ventevogel, P., Jefee-Bahloul, H., Barkil-Oteo, A. and Kirmayer, L.J. (2016), "Mental health and psychosocial wellbeing of Syrians affected by armed conflict", Epidemiology and Psychiatric Sciences, Vol. 25 No. 2, pp. 129-141.

Hoare, T., Vidgen, A. and Roberts, N. (2017), "In their own words: a synthesis of the qualitative research on the experiences of adults seeking asylum. A systematic review of qualitative findings in forced migration", Med Confl Surviv, Vol. 33 No. 4, pp. 273-298, [Review Systematic Review].

Hollifield, M., Verbillis-Kolp, S., Farmer, B., Toolson, E.C., Woldehaimanot, T., Yamazaki, J. and SooHoo, J. (2013), "The refugee health screener-15 (RHS-15): development and validation of an instrument for anxiety, depression, and PTSD in refugees", General Hospital Psychiatry, Vol. 35 No. 2, pp. 202-209, [Research Support, Non-U.S. Gov’t Validation Studies]

Hvidtfeldt, C., Schultz-Nielsen, M.L., Tekin, E. and Fosgerau, M. (2018), "An estimate of the effect of waiting time in the Danish asylum system on post-resettlement employment among refugees: separating the pure delay effect from the effects of the conditions under which refugees are waiting", PLoS One, Vol. 13 No. 11, p. 206737, [Research Support, Non-U.S. Gov’t].

Inter-Agency Standing Committee (2007), IASC Guidelines on Mental Health and Psychosocial Support in Emergency Settings, IASC, Geneva. 
Lietaert, I., Verhaeghe, F. and Derluyn, I. (2020), "Families on hold: how the context of an asylum centre affects parenting experiences", Child \& Family Social Work, Vol. 25 No. 1, p. 1, doi: 10.1111/ cfs. 12706.

Majumder, P., O'Reilly, M., Karim, K. and Vostanis, P. (2015), “'This doctor, I not trust him, I'm not safe': the perceptions of mental health and services by unaccompanied refugee adolescents", International Journal of Social Psychiatry, Vol. 61 No. 2, pp. 129-136.

Malkki, L. (1995), Purity and Exile. Violence, Memory and National Cosmology among Hutu Refugee in Tanzania, Chicago University Press, Chicago.

Malkki, L. (1996), "Speechless emissaries: refugees, humanitarianism, and dehistoricization", Cultural Anthropology, Vol. 11 No. 3, pp. 377-404.

Malkki, L. (2002), "News from nowhere. Mass displacement and globalized 'problems of organization'”, Ethnography, Vol. 3 No. 3, pp. 351-360.

Miller, K.E. and Rasmussen, A. (2010), "War exposure, daily stressors, and mental health in conflict and post-conflict settings: bridging the divide between trauma-focused and psychosocial frameworks", Social Science \& Medicine, Vol. 70 No. 1, pp. 7-16, doi: 10.1016/j.socscimed.2009.09.029.

MSF (2017), Life in Limbo - MSF's Psychosocial Support for Asylum Seekers in Sweden, Médecins Sans Frontières, Stockholm, available at: www.ecoi.net/en/file/local/1429704/1830_1529476994_1-msf-reportlife-in-limbo-web-eng.pdf

Posselt, M., Eaton, H., Ferguson, M., Keegan, D. and Procter, N. (2018), "Enablers of psychological wellbeing for refugees and asylum seekers living in transitional countries: a systematic review", Health \& Social Care in the Community, Vol. 27 No. 4, [Review].

Riley, A., Varner, A., Ventevogel, P. and Taimur Hasan, M.M. (2017), "Daily stressors, trauma exposure, and mental health among stateless Rohingya refugees in Bangladesh", Transcultural Psychiatry, Vol. 54 No. 3, pp. 304-331.

Rossenberger, S. and Konig, A. (2011), "Welcoming the unwelcome: the politics of minimum reception standards for asylum seekers in Austria", Journal of Refugee Studies, Vol. 25 No. 4.

Salvo, T. and Williams, A.C. (2017), "'If I speak English, what am I? I am full man, me': emotional impact and barriers for refugees and asylum seekers learning English", Transcultural Psychiatry, Vol. 54 Nos 5/6, pp. 733-755.

Tol, W.A., Barbui, C., Galappatti, A., Silove, D., Betancourt, T.S., Souza, R., Golaz, A. and van Ommeren, M. (2011), "Mental health and psychosocial support in humanitarian settings: linking practice and research", The Lancet), Vol. 378 No. 9802, pp. 1581-1591.

UNHCR (2020), "Global trends: forced displacement in 2019", UNHCR, Geneva, available at: www. unhcr.org/statistics/unhcrstats/5ee200e37/unhcr-global-trends-2019.html

van Berlaer, G., Bohle Carbonell, F., Manantsoa, S., de Bethune, X., Buyl, R., Debacker, M. and Hubloue, I. (2016), "A refugee camp in the centre of Europe: clinical characteristics of asylum seekers arriving in Brussels", BMJ Open, Vol. 6 No. 11, p. e013963, [research support, Non-U.S. Gov't].

van der Horst, H. (2004), "Living in a reception centre: the search for home in an institutional setting", Housing, Theory and Society, Vol. 21 No. 1, pp. 36-46.

Verroken, S., Schotte, C., Derluyn, I. and Baetens, I. (2018), "Starting from scratch: prevalence, methods, and functions of non-suicidal self-injury among refugee minors in Belgium", Child and Adolescent Psychiatry and Mental Health, Vol. 12 No. 1, p. 51.

WHO (2018), Report on the Health of Refugees and Migrants in the WHO European Region, WHO Regional Office for Europe, Copenhagen.

\section{Further reading}

American Psychiatric Association (2013), Diagnostic and Statistical Manual of Mental Disorders, 5th ed., Author, Arlington, VA.

American Psychological Association (2020), "APA dictionary of psychology", available at: https:// dictionary.apa.org/well-being (accessed 21 May 2020). 
AIDA and ECRE (2019), "COMPARATOR: compare key asylum indicators between 20 countries", available at: www. asylumineurope.org/comparator/reception (accessed 22 August 2020).

Baarnhielm, S., Edlund, A.S., Ioannou, M. and Dahlin, M. (2014), "Approaching the vulnerability of refugees: evaluation of cross-cultural psychiatric training of staff in mental health care and refugee reception in Sweden", BMC Medical Education, Vol. 14 No. 1, p. 207, [Research Support, Non-US Gov't].

Bell, P. and Zech, E. (2009), "Access to mental health for asylum seekers in the European Union. An analysis of disparities between legal rights and reality", Arch Public Heal, Vol. 67, p. 30.

Burrell, J. and Anderson, K. (2008), "I have great desires to look beyond my world': trajectories of information and communication technology use among Ghanaians living abroad", New Media \& Society, Vol. 10 No. 2, pp. 203-224.

European Union (2013), "Directive 2013/33/EU of the European parliament and of the council of 26 June 2013 laying down standards for the reception of applicants for international protection", EUR-Lex.

Fedasil (2018a), Bilan 2017: Accueil-Réinstallation et relocalisation-Retour Volontaire, Fedasil, Brussels.

Gorst-Unsworth, C. and Goldenberg, E. (1998), "Psychological sequelae of torture and organised violence suffered by refugees from Iraq. Trauma-related factors compared with social factors in exile", British Journal of Psychiatry, Vol. 172 No. 1, pp. 90-94. [Research Support, Non-U.S. Gov’t].

Hassan, G., Kirmayer, L., MekkiBerrada, A., Quosh, C., el Chammay, R., Deville-Stoetzel, J.B. and Ventevogel, P. (2015), Culture, Context and the Mental Health and Psychosocial Wellbeing of Syrians: A Review for Mental Health and Psychosocial Support Staff Working with Syrians Affected by Armed Conflict, UNHCR, Geneva.

Kaltenbach, E., Hardtner, E., Hermenau, K., Schauer, M. and Elbert, T. (2017), "Efficient identification of mental health problems in refugees in Germany: the refugee health screener", European Journal of Psychotraumatology, Vol. 8 No. 2, p. 1389205.

Kibreab, G. (1999), "Revisiting the debate on people. Place, identity, and displacement", Journal of Refugee Studies, Vol. 12 No. 4, pp. 384-410.

Morgan, G., Melluish, S. and Welham, A. (2017), "Exploring the relationship between postmigratory stressors and mental health for asylum seekers and refused asylum seekers in the UK", Transcultural Psychiatry, Vol. 54 Nos 5/6, pp. 653-674.

O’Donnell, C.A., Higgins, M., Chauhan, R. and Mullen, K. (2007), "'They think we're OK and we know we're not': a qualitative study of asylum seekers' access, knowledge and views to health care in the UK", BMC Health Services Research, Vol. 7 No. 1, p. 75.

Priebe, S., Giacco, D. and El-Nagib, R. (2016), "Public health aspects of mental health among migrants and refugees: a review of the evidence on mental health care for refugees", Asylum Seekers and Irregular Migrants in the WHO European Region Health Evidence Network Synthesis Report, WHO Regional Office for Europe, Copenhagen.

Robertshaw, L., Dhesi, S. and Jones, L.L. (2017), "Challenges and facilitators for health professionals providing primary healthcare for refugees and asylum seekers in high-income countries: a systematic review and thematic synthesis of qualitative research. [systematic review]", BMJ Open, Vol. 7 No. 8 , p. e015981.

Sierau, S., Schneider, E., Nesterko, Y. and Glaesmer, H. (2018), "Alone, but protected? Effects of social support on mental health of unaccompanied refugee minors", European Child \& Adolescent Psychiatry, Vol. 28 No. 6.

World Health Organization (2004), "Promoting mental health: concepts, emerging evidence, practice (summary report)", World Health Organization, Geneva, available at: www.who.int/mental_health/ evidence/en/promoting_mhh.pdf

WHO (2006), Constitution of the World Health Organisation - Basic Documents, WHO, Geneva.

Author affiliations

Katherine Whitehouse is based at Luxembourg Operational Research Unit, Medecins Sans Frontieres, Brussels, Belgium.

Ella Lambe and Sofia Rodriguez are both based at Operations Department, Medecins Sans Frontieres, Brussels, Belgium. 
Umberto Pellecchia is based at Luxembourg Operational Research Unit, Medecins Sans Frontieres, Brussels, Belgium.

Aurelie Ponthieu is based at Analysis Department, Medecins Sans Frontieres, Brussels, Belgium.

Rafael Van den Bergh is based at Luxembourg Operational Research Unit, Medecins Sans Frontieres, Brussels, Belgium.

Djoen Besselink is based at Operations Department, Medecins Sans Frontieres, Brussels, Belgium.

\section{Corresponding author}

Katherine Whitehouse can be contacted at: kitwhitehouse@gmail.com

For instructions on how to order reprints of this article, please visit our website: www.emeraldgrouppublishing.com/licensing/reprints.htm

Or contact us for further details: permissions@emeraldinsight.com 